\title{
Analysis of the Integration and Dynamic Linkages of BRICS Stock Markets
}

\author{
Zehui $\mathrm{Yu}^{1 *}$, Liru Bai ${ }^{2}$, Yiming $\mathrm{Li}^{2}$ \\ ${ }^{1}$ School of Innovation and Entrepreneurship, Shandong Women's University, Jinan, Shandong 250000, China \\ ${ }^{2}$ School of Economic and Trade, Shandong Management University, Jinan, Shandong 250000, China \\ *Corresponding author.Email: yzh_sdwu@163.com
}

\begin{abstract}
In the past decade, BRICS countries have become the main driver of global economic growth. China, as a major member of BRICS, has gradually opened up its own capital market and gained ever-growing interconnection with global capital markets, with the implement the QFII and QDII system. Therefore, it is of great significance to explore the stock markets linkage between China and other BRICS nations. In this paper, it focuses on the long-term equilibrium relations and short-term dynamic linkage among the BRICS stock markets, and uses such tools as cointegration test, causality test, impulse-response and variance decomposition, to analyze the correlation of representative stock indexes in BRICS countries. The empirical results show that, in the long term and the short term, there is a clear stock correlation among the BRICS markets. In the long run, there is a reliable co-integration relationship among all the stock markets. Moreover, Granger causality test results show that China's stock market is influenced by other countries instead of influencing others, and most of the causal relationships are bidirectional. In the short run, the results of impulse-response and variance decomposition show that China's market volatility has the largest and most obvious spillover effect on other countries' stock markets. This paper will help the authorities of BRICS with the formulation of macroeconomic policies as well as the establishment of regulatory mechanisms, and the investors with rational investment strategy.
\end{abstract}

Keywords: BRICS Nations, Linkage of Stock Market, VAR Model, Co-integration

\section{INTRODUCTION}

The term of BRICS nations, including Brazil, Russia, India, China and South Africa, was first put forward in 2001 to refer specifically to the global emerging market, for member countries of BRICS are all underdeveloped countries. Since the 21st century, the BRICS countries have developed at a fast pace, and at the same time the international influences of the BRICS countries have gradually increased. The proportion of BRICS countries' GDP to global GDP is rising gradually, as shown in Figure 1. BRICS countries' share of world GDP has gone from $10.8 \%$ in 2012 to $20.7 \%$ in 2020 , making outstanding contribution to global economic growth.

With the advancement of economic globalization, China continues to raise the level and quality of opening-up through deep reforms, such as QFII and QDII system. In the meantime, trade ties among the member nations of the BRICS are increasingly close, with China being the largest exporter of Brazil and South Africa as well as the third largest exporter of India. The expansion of international trade certainly enhances the capital flow in financial market and the dependence of the real economy in BRICS countries. The stock market of one country can directly represent its economic operation status, not only reflecting the economic development of its own country, but also responding to the economic development of other countries to a certain extent. In consequence, this paper will analyze the integration and dynamic linkage of stock markets in BRICS countries, to prevent the negative impact of external risks from other emerging economies, to formulate efficient macroeconomic and risk regulation policies, and to guide the investors to make reasonable investment plans. 


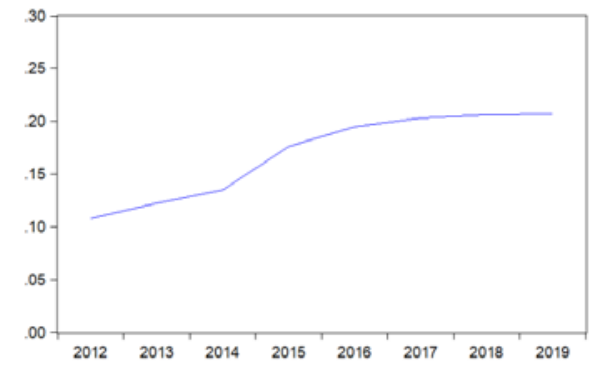

Figure 1 The proportion of BRICS countries' GDP to global GDP

\section{RELATED RESEARCH REVIEW}

With the gradual advancement of economic globalization, the BRICS economies have stepped into a stage of rapid development and their international influence has been gradually enhanced. As the BRICS countries have become a new engine of world economic development, there is a ton of research on the correlation among the BRICS stock markets. Dasgupta (2014) studied the long-term and short-term correlation among BRIC countries, BRICS nations without South Africa. Puah et al. (2015) adopted the co-integration test and revealed the long-term co-integration relationship of the BRICS stock markets. He also used the Granger causality test to conclude that the volatility of China stock market Granger causes the volatility of other BRICS stock markets. Cheng (2016) analyzed monthly trade data from 2001 to 2015 by using stationary and causal methods, with results showing that the financial crisis strengthened the correlation between the US stock market and the BRICS stock markets. Singh and Gandhi (2014) as well as Jain (2016) found the long-term correlation among the five stock markets by the Johansen co-integration test. Wang (2016) and Yu (2016) argue that the subprime mortgage crisis affected the linkage among stock markets of various countries to different degrees.

The previous and numerous studies on the linkage of BRICS stock markets mainly discuss the long-term equilibrium relationship, while few studies on the shortterm spillover effect of stock markets, which cannot fully reflect the real situation of the stock linkage. Accordingly, from the perspective of long-term and short-term, this paper conducts an in-depth and detailed study on the linkage effect of the BRICS stock markets, so as to provide reasonable policy suggestions for investors and government departments.

\section{EMPIRICAL ANALYSIS}

\subsection{Data Processing and Descriptive Statistics}

In this article, it selects the IBOVESPA index issued by the BM\&FBOVESPA, MICEX index issued by the MOEX, SENSEX index issued by the BSE, GTR index issued by HKEx, and TOP 40 index issued by JSE to represent the stock markets of Brazil, Russia, India, China and South Africa, the BRICS member countries. The trading data from May 22, 2012 to August 31, 2020 are chosen as observations, including the closing price and daily return rate. Variable declarations are indicated in Table 1. The trading day of five markets is not exactly the same, but there are overlapped days, hence the sample observed are 1784 in total, excluding the dates when the five markets do not all open. The software used in this article is Eviews.

The closing prices of BRICS stock markets are shown in Figure 2. It can be obviously seen that extremely strong similarity in the stock trends of the BRICS countries exists, with the stock indexes of Russia and Brazil having a relatively large increase and that of other countries having small increases. All stock indexes showed a sharp decline in late 2019 and early 2020, possibly due to the negative impact of COVID-19 on the global economy. It's important to note that the GTR index, on behalf of the China stock market index, did not change significantly in the past years, as the figure shows. The possible explanation is that enterprises covered in GTR index are limited, unable to represent the broader stock market in China. However, given the condition that cross-border capital flows may affect the linkage of stock markets and the stock market in mainland China is in gradual process of opening up, the Hong Kong stock market is relatively more open and suitable to be included in BRICS stock markets. Therefore, GTR index is retained to represent the China stock market.

The descriptive statistics of the closing prices of BRICS stock markets are shown in Table 2. The higher standard deviations of the Russian and Brazilian stock markets indicate frequent and violent market fluctuations, which can also be seen from Figure 2. It can be seen that the kurtosis of China's closing price is higher than 3, the kurtosis of standard normal distribution, showing the characteristics of sharp peak and heavy tail, while the distribution of India is more gentle. Besides, from the results of Jarque-Bera test, the null hypotheses that closing prices are normally distributed are rejected in all markets.

In order to study the co-movement of BRICS stock markets, the changes in their stock returns need to be examined. Based on the analysis of stock returns, the short-term volatility spillover effects, as well as the long-term equilibrium relationship among stock markets of BRICS countries can be determined. The descriptive statistics of daily returns are shown in Table 3. Firstly, it can be seen that the average returns of Brazil, Russia and South Africa are positive, in which the South African stock market has the best performance. Secondly, Indian stock market is the safest, with the lowest standard deviation. Thirdly, the skewness shows 
negative bias in stock returns of Brazil and Russia, implying declines in the two markets are normal. Finally, compared with kurtosis of 3 in normal distribution, all stock returns distributions are tend to have sharp peak and heavy tail, which means the probability of extreme observations is very high. Also, the null hypothesis of normal distribution are all rejected in five countries.

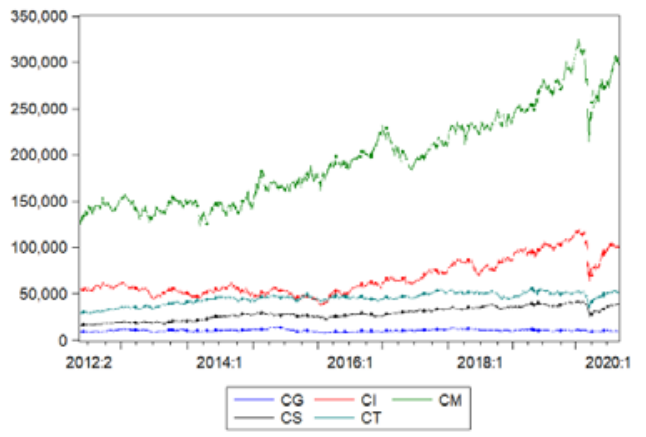

Figure 2 Closing prices of BRICS stock markets

Table 1 Variable declarations

\begin{tabular}{|c|c|c|c|}
\hline Variables & Definition & Variables & Definition \\
\hline $\mathrm{CG}$ & Closing price of GTR & $\mathrm{RG}$ & Daily return of GTR \\
\hline $\mathrm{Cl}$ & Closing price of IBOVESPA & $\mathrm{Rl}$ & Daily return of IBOVESPA \\
\hline $\mathrm{CM}$ & Closing price of MICEX & $\mathrm{RM}$ & Daily return of MICEX \\
\hline $\mathrm{CS}$ & Closing price of SENSEX & $\mathrm{RS}$ & Daily return of SENSEX \\
\hline $\mathrm{CT}$ & Closing price of TOP4O & $\mathrm{RT}$ & Daily return of TOP4O \\
\hline
\end{tabular}

* denotes rejection of the hypothesis at the $5 \%$ level

** denotes rejection of the hypothesis at the $1 \%$ level

Table 2 Descriptive statistics of BRICS countries' closing prices

\begin{tabular}{|c|c|c|c|c|c|}
\hline Variables & Mean & Std. Dev & Skewness & Kurtosis & Jarque-Bera \\
\hline CG & 10579.84 & 1122.565 & 0.677675 & 4.446454 & $292.0709^{* *}$ \\
\hline Cl & 67352.95 & 19534.05 & 0.862538 & 2.583690 & $234.0908^{* *}$ \\
\hline CM & 196610.8 & 49867.98 & 0.538530 & 2.246625 & $128.4207^{* *}$ \\
\hline CS & 28652.37 & 6812.906 & 0.044115 & 1.968997 & $79.59250^{* *}$ \\
\hline CT & 45251.83 & 6096.494 & -0.824653 & 3.058886 & $202.4599^{* *}$ \\
\hline
\end{tabular}

* denotes rejection of the hypothesis at the $5 \%$ level

** denotes rejection of the hypothesis at the $1 \%$ level

Table 3 Descriptive statistics of BRICS countries’ stock returns

\begin{tabular}{|c|c|c|c|c|c|}
\hline Variables & Mean & Std. Dev & Skewness & Kurtosis & Jarque-Bera \\
\hline RG & -0.000665 & 0.010325 & 0.125764 & 5.715349 & $552.7715^{* *}$ \\
\hline RI & 0.000392 & 0.016167 & -0.532442 & 15.21460 & $11174.56^{* *}$ \\
\hline RM & 0.000488 & 0.011098 & -0.234731 & 7.911383 & $1809.428^{* *}$ \\
\hline RS & -0.001097 & 0.009273 & 0.329464 & 16.53909 & $13658.09^{* *}$ \\
\hline RT & 0.002627 & 0.012150 & 1.166131 & 6.853618 & $1508.209^{* *}$ \\
\hline
\end{tabular}

* denotes rejection of the hypothesis at the $5 \%$ level

** denotes rejection of the hypothesis at the $1 \%$ level

\subsection{Unit Root Test}

Considering that BRICS countries are located in four continents and have different economic, political and cultural backgrounds, it is more appropriate to build VAR model to study the characteristics of stock returns, because VAR model emphasizes more on the effects rather than the causes of changes. The establishment of VAR model requires stationarity of all stock returns, so as to avoid the problem of pseudo regression that financial time series often have. Moreover, the study of long-term equilibrium relationship is based on the premise that all stock returns are stationary. Therefore, the $\mathrm{ADF}$ test is adopted in this paper to test the stationarity of the BRICS stock returns. When there is one unit root, the stock return is unstable, otherwise it is stable.

The results of Augmented Dickey-Fuller test are shown in Table 4. At the significance level of $1 \%$, the null hypothesis of having unit root are all rejected in all BRICS countries, so the stock returns are all stationary, which can be used for co-integration test and VAR model construction. 
Table 4 ADF test on BRICS stock returns

\begin{tabular}{|c|c|c|c|c|c|}
\hline Variables & $(\mathrm{C}, \mathrm{T}, \mathrm{L})$ & T-statistics & $\begin{array}{c}\text { 1\% Critical } \\
\text { Value }\end{array}$ & $\begin{array}{c}5 \% \text { Critical } \\
\text { Value }\end{array}$ & $\begin{array}{c}10 \% \text { Critical } \\
\text { Value }\end{array}$ \\
\hline $\mathrm{RG}^{* *}$ & $(\mathrm{C}, \mathrm{O}, 1)$ & -42.33909 & -3.433815 & -2.862957 & -2.567572 \\
\hline $\mathrm{R}^{* *}$ & $(\mathrm{C}, \mathrm{O}, 1)$ & -45.35666 & -3.433815 & -2.862957 & -2.567572 \\
\hline $\mathrm{RM}^{* *}$ & $(\mathrm{C}, \mathrm{O}, 1)$ & -43.63093 & -3.433815 & -2.862957 & -2.567572 \\
\hline $\mathrm{RS}^{* *}$ & $(\mathrm{C}, \mathrm{O}, 1)$ & -45.45783 & -3.433815 & -2.862957 & -2.567572 \\
\hline $\mathrm{RT}^{* *}$ & $(\mathrm{C}, \mathrm{O}, 1 \mathrm{O})$ & -4.318547 & -3.433836 & -2.862966 & -2.567576 \\
\hline
\end{tabular}

* denotes rejection of the hypothesis at the $5 \%$ level

$* *$ denotes rejection of the hypothesis at the $1 \%$ level

\subsection{Co-integration Test}

Since the return rates of BRICS countries are stationary, the long-term equilibrium relationship among them can be analyzed by using the co-integration test. As it involves co-integration test among multiple variables, Johansen test is adopted and the results are listed in Table 5, with the lag orders to be 10 . Most obviously, the null hypothesis of no co-integration relationship, and that of there being one, two or three co-integration relationships at most are all rejected, while that of having 4 co-integration relationships at most is accepted at the significance level of $1 \%$, which means, among the five stock returns, there are four co-integration relationship. Therefore, there is a stable equilibrium relationship among the BRICS stock markets in the long run.

Table 5 Johansen co-integration test results of BRICS stock returns

\begin{tabular}{|c|c|c|c|c|}
\hline Null Hypothesis & Eigenvalue & Trace Statistic & 5\% Critical Value & Prob. \\
\hline None $^{* *}$ & 0.099230 & 603.3307 & 69.81889 & 0.0001 \\
\hline At most $1^{* *}$ & 0.075689 & 418.0424 & 47.85613 & 0.0001 \\
\hline At most 2 & 0.074646 & 278.4962 & 29.79707 & 0.0001 \\
\hline At most 3* & 0.068453 & 140.9490 & 15.49471 & 0.0001 \\
\hline At most 4 & 0.008552 & 5.22746 & 13.841466 & 0.0602 \\
\hline
\end{tabular}

* denotes rejection of the hypothesis at the $5 \%$ level

** denotes rejection of the hypothesis at the $1 \%$ leve

\subsection{Granger Causality Test}

Since there is a long-term co-integration relationship among the BRICS stock markets, it is necessary to determine whether there is an influence among the stock markets and the direction of it. Hence, Granger causality test is conducted on the stock returns of BRICS nations, and the results are shown in Table 6. In order to show the impact and effect more visually, Figure 3 below shows the relationship diagram of five stock returns. At the 95\% confidence level, India is at the center of the Cause and effect diagram. It affects the other four countries, only being affected by Russia and Brazil. China has the weakest ability to influence, affecting only South Africa and being influenced by Russia and India. Also, in the diagram, most of the influencing paths are bidirectional, which works between Russia and Brazil, between Russia and India, between India and Brazil, between India and South Africa, as well as between Brazil and South Africa. On the whole, the interaction among the BRICS stock markets is beyond dispute.

Table 6 Granger causality test results of BRICS stock returns

\begin{tabular}{|l|l|c|c|}
\hline \multicolumn{2}{|c|}{ Null Hypothesis } & F-Statistic & Prob. \\
\hline \multirow{4}{*}{ RG does not Granger Cause: } & $\mathrm{RI}$ & 2.14204 & 0.0580 \\
\cline { 2 - 4 } & $\mathrm{RM}$ & 1.24434 & 0.2858 \\
\cline { 2 - 4 } & $\mathrm{RS}$ & 1.68899 & 0.1340 \\
\cline { 2 - 4 } & $\mathrm{RT}^{*}$ & 2.74463 & 0.0178 \\
\hline \multirow{4}{*}{ RI does not Granger Cause: } & $\mathrm{RG}$ & 1.14254 & 0.3356 \\
\cline { 2 - 4 } & $\mathrm{RM}^{* *}$ & 5.92978 & 0.0000 \\
\cline { 2 - 4 } & $\mathrm{RS}^{* *}$ & 4.22267 & 0.0008 \\
\cline { 2 - 4 } & $\mathrm{RT}^{* *}$ & 8.31897 & 0.0000 \\
\hline RM does not Granger Cause: & $\mathrm{RG}^{*}$ & 2.58617 & 0.0244 \\
\hline
\end{tabular}




\begin{tabular}{|c|c|c|c|}
\hline & $\mathrm{R} \mathrm{N}^{*}$ & 2.80324 & 0.0158 \\
\hline & RS & 1.52715 & 0.1781 \\
\hline & $\mathrm{RT}^{* *}$ & 7.44700 & 0.0000 \\
\hline \multirow{4}{*}{ RS does not Granger Cause: } & $R G^{* *}$ & 3.53383 & 0.0035 \\
\hline & $\mathrm{R}^{* *}$ & 6.47945 & 0.0000 \\
\hline & $\mathrm{RM}^{* *}$ & 3.53510 & 0.0035 \\
\hline & $\mathrm{RT}^{* *}$ & 7.83288 & 0.0000 \\
\hline \multirow{4}{*}{ RT does not Granger Cause: } & $R G$ & 0.73473 & 0.5974 \\
\hline & $\mathrm{R}^{*}$ & 2.79802 & 0.0160 \\
\hline & $\mathrm{RM}$ & 0.44530 & 0.8169 \\
\hline & $\mathrm{RS}^{* *}$ & 4.36358 & 0.0006 \\
\hline
\end{tabular}

* denotes rejection of the hypothesis at the $5 \%$ level

** denotes rejection of the hypothesis at the $1 \%$ level

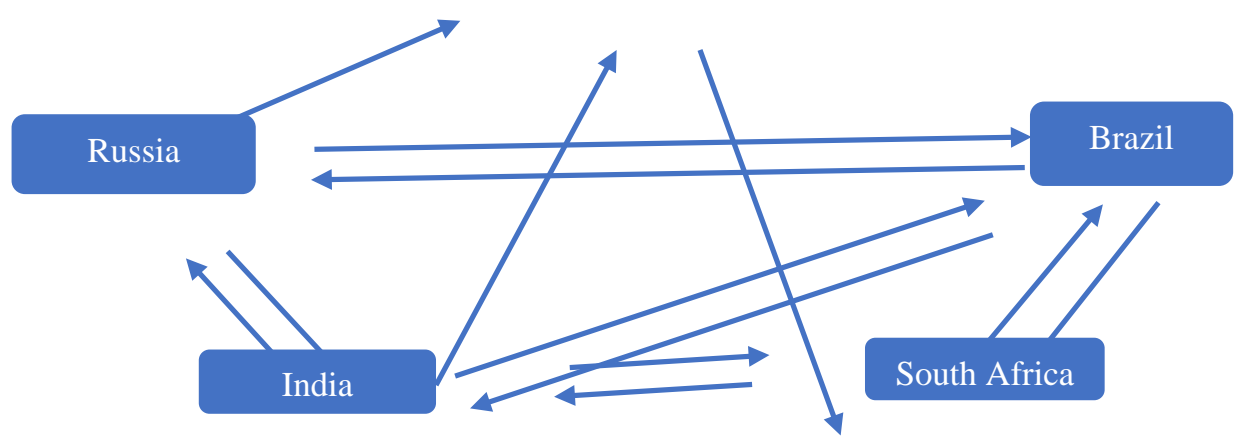

Figure 3 Causal relationship of BRICS countries’ stock markets

\subsection{Dynamic Linkage Analysis}

\subsubsection{VAR Modeling}

According to the ADF test results mentioned above, all the stock returns of BRICS countries are stationary, so the VAR model can be built to explore the short-term spillover effect among them, focusing on the transmission of market fluctuations. When establishing the VAR model, the lag order should be determined first according to AIC and SC information criteria, with the trial results of different lag orders in Table 7 . In the light of AIC, lag order of 6 should be selected, while according to SC the lag order is 2. Considering that the difference of SC between second-order lags and sixthorder lags is not significant, and the AIC of sixth-order lags is much less than that of order 2, the lag order of VAR model is chosen to be 6

Table 7 Information Criterion in different lags of VAR

\begin{tabular}{|c|c|c|}
\hline Lags & AlC & SC \\
\hline 1 & -31.03967 & -30.94736 \\
\hline 2 & -31.16117 & $-30.99186 *$ \\
\hline 3 & -31.22485 & -30.97847 \\
\hline 4 & -31.25248 & -30.92897 \\
\hline 5 & -31.28964 & -30.88892 \\
\hline 6 & $-31.30366 *$ & -30.82564 \\
\hline 7 & -31.30291 & -30.74754 \\
\hline
\end{tabular}

\subsubsection{Impulse-Response Analysis}

After building the VAR model, this paper describes the degree of response of BRICS stock markets to external shocks through impulse-response analysis. The impulse function reflects the dynamic changes of each stock return of BRICS countries in the current and the following periods, after it is impacted by a standard unit error of other stock return. It visualizes the variation of endogenous variables in the current period and future period.

The lag periods of the impulse-response is set to be 10, as shown in Figure 4. In the impulse-response diagram, the abscissa represents the different stages and the ordinate represents the impact each stock return received. What can be seen from the figure is that, for BRICS nations, the response to their own impulse are obvious but declined rapidly in the previous two periods, which did not last for a long time. For China, the influence of other BRICS countries is not significant, response being around 0 . For Brazil, the impact of China was evident in the first phase. The influence of China and Brazil is significant for both Russia and India. Finally, the impact of other countries will all bring significant changes on South Africa.

To sum up, first of all, the responses degree of the five countries to their own shocks are overwhelmingly greater than the response degree to the other BRICS countries. Second, only China has influence on all the 
other nations on a large scale. Finally, the dynamic

but only one-way generally. linkage among BRICS countries is relatively obvious,
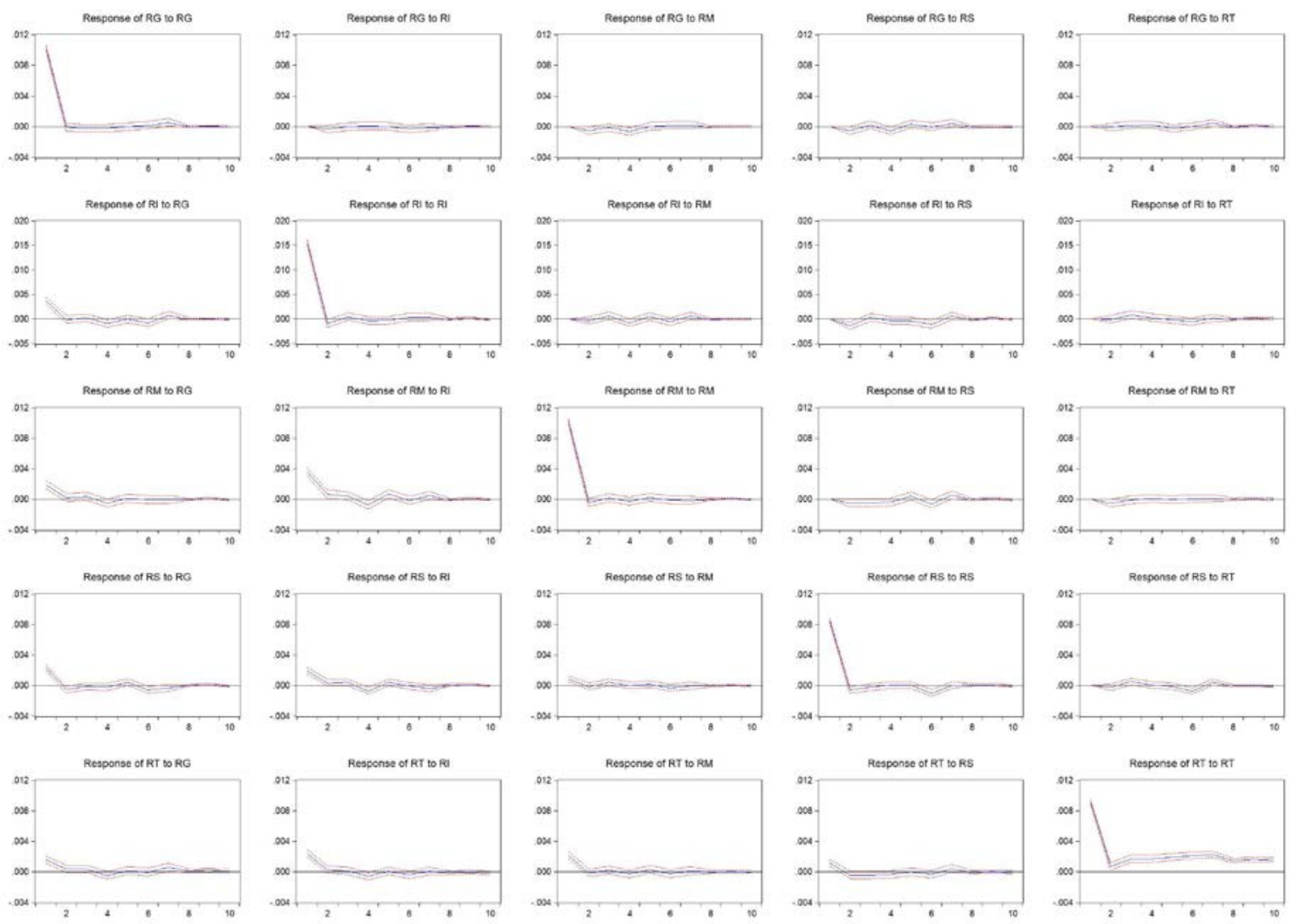

Figure 4 Impose-Response of BRICS countries’ stock returns3.5.3. Variance Decomposition

Based on the VAR model, variance decomposition can also be carried out for the stock returns of BRICS countries, to explore, at a certain time, how much of the variance of return rates is caused by itself and how much is caused by changes of other countries. Variance predictions are made for all stock returns for 10 periods and the results of the 10th period are listed in Table 8 . As shown from the table, $97 \%$ stock changes of China is affected by itself, while other BRICS countries have a relative small influence on it, with the influence of Brazil being the smallest. For the other BRICS countries, their own influence is the largest, while the second largest source of influence varies from country to country. Except for the affected countries themselves, China has the most influence on Brazil and India, and Brazil has the most influence on Russia and South Africa. In summary, China and Brazil are the most influential countries in BRICS

Table 8 Variance decompositions of stock returns

\begin{tabular}{|c|c|c|c|c|c|}
\hline & RG & RI & RM & RS & RT \\
\hline RG & 97.87752 & 0.211742 & 0.714446 & 0.847213 & 0.349082 \\
\hline RI & 5.778192 & 91.48902 & 0.814897 & 1.493578 & 0.424317 \\
\hline RM & 3.186654 & 11.85005 & 83.53360 & 1.158640 & 0.271053 \\
\hline RS & 7.260406 & 5.446351 & 1.198506 & 84.86948 & 1.225254 \\
\hline RT & 2.625607 & 5.049726 & 3.962361 & 1.688672 & 86.67363 \\
\hline
\end{tabular}

\section{CONCLUSION}

In conclusion, both in the short run and the long run, the integration and dynamic linkage among BRICS stock markets are significant by empirical test. In the long run, there is a reliable co-integration relationship among all the stock markets. Moreover, Granger causality test results show that China's stock market is influenced by other countries instead of influencing others, and most of the causal relationships are bidirectional. In the short run, the results of impulseresponse and variance decomposition show that China's market volatility has the largest and most obvious spillover effect on other countries' stock markets. 
Therefore, with the pace of the opening up of China capital market, it will be connected to the global stock market increasingly. On the one hand, against this background, the investors can allocate their assets not only in the domestic capital market but also in the international capital market, to reduce risks by diversification strategy and to increase expected stock returns. However, since each stock market has different ways to respond to the same external economic shock, investors are supposed to make decisions prudently to avoid unnecessary investment losses caused by stock market linkage. On the other hand, for the authorities, it is necessary to strengthen international communication and cooperation, and to establish a cross-border regulatory mechanism, further improving the investment environment of the domestic capital market and enhancing the efficiency of capital flows.

\section{REFERENCES}

[1] R. Dasgupta, Integration and dynamic linkages of the indian stock market with BRICS-an empirical study, Asian Economic and Financial Review, 2014, pp. 715-731.

[2] C.H. Puah, R.K. Brahmana RK, K.H. Wong, Revisiting Stock Market Integration Pre-Post Subprime Mortgage Crisis: Insight from BRICS Countries, Economics \& Finance in Indonesia, 2015, pp. 61-65. DOI: https://doi.org/10.7454/efi.v61i2.507

[3] B. Cheng, Comparative Research on the Connection of Stock Markets Between China-U.S. and BRICS, Journal of scientific innovation and productivity, 2016, pp. 34-37. DOI: https://doi.org/10.3969/j.issn.16749146.2016.03.034

[4] R.P. Singh, M. Gandhi, A Study of Causality and Co- Integration Effect Among the BRICS Countries Stock Exchanges - A Relationship Study, Business Rethinking in 21st Century, 2014.

[5] N. Jain, The Interdependence Between Stock Markets-An Econometric Study of BRICS Nations, International Journal of Research in Economics and Social Sciences, 2016, pp. 120-132.

[6] Y. Wang, The linkage effects of China and other BRICS countries' stock markets, Ph.D. Thesis, JiLin University of Finance and Economics, 2016.

[7] H.L. Yu, The study of co-movement among BRICS stock markets, Ph.D. Thesis, Liaoning University, 2016. 